\title{
Innovación Desde La Docencia Para El Logro De Habilidades En El Aula
}

\section{Innovation From Teaching For The Achievement Of Skills In The Classroom}

Mg. Maritza Guzmán Matamala

Coordinación Orientación y Consejo de Curso. Escuela de Pedagogía. Facultad de Educación, Ciencias Sociales y Humanidades. Universidad de la Frontera.mgm.maritza@gmail.com

\section{Resumen}

El propósito del presente trabajo es abordar la necesidad manifestada por diversos actores de Instituciones Educativas chilenas de la región de la Araucanía, quienes considerando la constante y vertiginosa evolución de nuestra sociedad, observan que el factor humano se ha visto debilitado por ausencia de métodos e instrumentos suficientes como para enfrentar estos nuevos desafíos, donde la innovación personal juega un rol preponderante en términos de docencia. Se pretende promover e instalar la importancia de tener instancias de reflexión para aquellos educadores interesados en la mejora de la calidad de habilidades para la entrega de aprendizajes significativos contemplando metodologías que apunten a un trabajo colaborativo en equipo desde su individualidad y que genere consecuencias de auto-reflexión y crecimiento personal. Se considerarán temáticas como la fenomenología del conocer, asertividad y competencias profesionales necesarias para enfrentar las nuevas exigencias educativas, revelando la importancia del contenido en la formación, promoviendo el pensamiento crítico de la práctica docente y optimizando la retroalimentación como una herramienta importante que se puede integrar intencionada y reflexivamente a los procesos educativos y que se nutre día a día con la experiencia docente que invita a trabajar con equidad, eficiencia y aspiraciones de excelencia.

Palabras clave: Docente, innovación, asertividad, reflexión.

\footnotetext{
Abstract

The purpose of this paper is to address the need expressed by various actors of Chilean region of Araucania educational institutions, those considering the constant and rapid evolution of our society, observed that the human factor has been weakened by the absence of adequate tools and methods to meet these new challenges, where the personal innovation plays a predominant in terms of teaching role. It aims to promote and install the importance of having instances of reflection for those educators interested in the improvement of the quality of skills for the delivery of significant learning at that point to a collaborative
} 
teamwork from his individuality and methodologies that generate consequences of self-reflection and personal growth. Themes will be considered as the phenomenology of knowing, assertiveness and professional skills needed to face new educational demands, revealing the importance of the training content, promoting critical thinking in the teaching practice, and optimizing feedback as an important tool that can integrate intentionally and thoughtfully to educational processes and he thrives every day with the teaching experience that invites to work. with equity efficiency and aspirations of excellence.

Keywords: educational innovation, assertiveness, reflection.

\section{Introducción}

El propósito del presente trabajo es abordar la necesidad manifestada por diversos actores de Instituciones Educativas chilenas de la región de la Araucanía, quienes considerando la constante y vertiginosa evolución de nuestra sociedad, observan que el factor humano se ha visto debilitado por ausencia de métodos e instrumentos suficientes como para enfrentar estos nuevos desafíos, donde la innovación personal juega un rol preponderante en términos de docencia.

Por lo tanto uno de los objetivos para el desarrollo de este trabajo es analizar cómo se expresan las prácticas formativas, fomentando la reflexión en cuanto a la acción educativa; dinamizando la construcción del pensamiento crítico, asertividad y competencias profesionales, pudiendo de esta manera establecer que la retroalimentación educativa es una herramienta sustentable para la innovación pedagógica.
En síntesis, entenderemos que la innovación desde la docencia para las habilidades en el aula, se manifiesta más que en la transferencia de contenidos y/o conocimientos, en la praxis que trasciende hacia la educación misma de modo transversal, considerando la formación integral como meta, en el contexto en que se movilizan los docentes de hoy; los que deben tener una preparación más acabada en temáticas de valores, de autoconocimiento y en definitiva educadores dispuestos a enfrentar un nuevo escenario educacional. Esta nueva mirada desde la docencia, permitirá el encuentro y sensibilidad de aquellos hombres y mujeres que decidieron entregar su vida al servicio educacional, que lamentablemente en la actualidad se encuentra abatido por políticas no resueltas.

\section{Desarrollo}

\subsection{Situación actual de la docencia frente a la innovación.}

Actualmente en nuestro país, la innovación, como demanda y discurso, se ha establecido en 
los más variados ámbitos. En educación, la necesidad de innovar se ha situado en el centro del debate, obligándonos como docentes a reexaminar tradiciones y a reflexionar sobre la vigencia y pertinencia de nuestras prácticas y procedimientos.

La persistencia de antiguas formas de hacer educación, la constante exigencia por parte del Ministerio integrando cada vez más, nuevas cargas académicas manteniendo el mismo salario con un agregado de desgate emocional, los petitorios por parte de Directivos, Padres y Apoderados, Pares Académicos, Estudiantes e incluso la auto exigencia que el docente enfrenta, sin dejar de mencionar la irrupción de nuevos obstáculos que aparecen en el escenario educativo y que desafían permanentemente nuestra creatividad, o la obtención de resultados o logros parciales y de relativo impacto.

Es necesario recordar que los maestros y maestras son la pieza clave del aprendizaje en el aula. Por lo que se requieren fundamentos $y$ estrategias para re encantar la educación y sus actores. Y este es uno de los motivos poderosos de este trabajo el cual pretende volver a dar relevancia a la docencia, a quienes permiten el avance y prosecución de la educación en Chile y en cualquier parte del mundo, es necesario encontrar nuevamente el sentido del trabajo educativo donde cada docente se enfrenta consigo mismo, con su propia moral profesional, con la educación y por sobre todas las cosas con el deseo de innovar entendiendo el concepto pleno que iremos construyendo en este artículo.

El sector educativo y la sociedad civil reconocen la necesidad de una educación de calidad que proporcione a los estudiantes conocimientos relevantes, tanto para su inserción al trabajo como adultos como para realizarse y trascender como personas. A la vez, "numerosos estudios muestran que lo que sucede en el aula y la influencia del profesor son la variable crucial para mejorar los resultados escolares. El método utilizado por el docente es de suma importancia en cualquier reforma destinada a mejorar la calidad." (UNESCO 2004:171). Muchos educadores proponen desarrollar procesos educativos activos, en los cuales se involucre al estudiante como sujeto y participante, y donde los docentes no sean simples proveedores de información e instrucciones, sino facilitadores de la construcción de conocimiento por los mismos estudiantes.

Paradójicamente, la noción de educación activa que se aplica a los estudiantes con frecuencia no se extiende a los maestros y maestras. A menudo, se asume que los docentes, tratados como recurso pasivo para implementar la política educativa, podrán luego producir transformación en el aula. A veces se actúa como que bastara con darles instrucciones para que cumplan con lo que se les dice y cuando no lo hacen, se asume que los docentes o no entienden, o se resisten a lo nuevo, o no están comprometidos con la enseñanza. Además, los medios de comunicación y otros 
formadores de opinión pública a veces presentan una imagen negativa de los maestros como resistentes a la innovación y sin interés por el aprendizaje. Sin embargo, los maestros y maestras son el eje en torno al cual se construye el aprendizaje efectivo, son las personas a quienes les toca encontrar soluciones a los desafíos que se presentan a diario en el aula y con los estudiantes.

Es positivo y necesario insistir en que la pieza clave que permite el desarrollo de un aprendizaje efectivo en el aula es un maestro o maestra con las competencias necesarias para atender a la diversidad de estudiantes y situaciones que enfrenta. La capacidad para adecuar su práctica a las necesidades de cada grupo de estudiantes y a cada estudiante en sus circunstancias particulares es una parte importante de dicha competencia docente. En ello, la innovación docente, entendida como la capacidad para hacer cosas nuevas, o para hacer cosas conocidas de forma diferente en el aula, la escuela y la comunidad, es fundamental para dar una base concreta a una nueva forma de hacer o construir la educación.

Innovar en las prácticas cotidianas de la gestión de la docencia, constituye un desafío que adquiere una dinámica permanente y constante, pues ante cada logro de la innovación surge de inmediato la necesidad de volver a empezar. Ahí radica la permanencia de este esfuerzo: nunca se termina de innovar, de crear, de pensar.
No se puede olvidar que los docentes son socios en la reforma educativa. Es hora de verlos como creadores e innovadores, y no sólo como instrumentos para implementar la política.

\subsection{Acercamiento a un análisis conceptual de Innovación.}

Los cambios estructurales en el sistema educativo actual, han sido evidenciados paulatinamente, producto del movimiento permanente de dinámicas sociales propias de esta era globalizada. Los distintos actores del mundo de la educación se han visto obligados a redefinir roles, tareas, funciones y compromisos, con el fin de mejorar el acceso a las oportunidades que ofrece la era global y la calidad de los procesos que se desarrollan. Parece trascendente que confluyan instituciones públicas y privadas, que bajo un único propósito, se aboquen a la tarea de construir propuestas educativas innovadoras $y$ transformadoras, pero no solo eso, sino también lograr motivar a quienes llevan adelante estos propósitos. Los educadores.

Para continuar analizando el tema, es interesante poder responder algunas preguntas... ¿Qué es innovación? ¿Qué conceptos están relacionados con la innovación? ¿Soy un educador innovador? ¿Existen resultados que avalen los procesos de innovación que he realizado? 
Es posible enunciar que Innovar hace referencia a mejorar, cambiar, transformar, lograr resultados, "abrir la mente" y en este caso por qué no, tomar desde lo creado y generar nuevas experiencias de aprendizaje.

Según el diccionario de la Real Academia Española, la innovación, es la creación o modificación de un producto, y su introducción en un mercado. Innovar proviene del latín innovare, que significa acto o efecto de innovar, tornarse nuevo o renovar, introducir una novedad.

Saturnino de la Torre conceptualiza innovación de la siguiente manera:

\footnotetext{
'La innovación como expresión social y colaborativa de la creatividad es posible entenderla en términos de resultado, la innovación es uno de los niveles más altos de creatividad. Integra categorias como iniciativa, inventiva, originalidad, disposición al cambio, aceptación del riesgo, proceso adaptativo, pero sobre todo colaboración y disposición a compartir valores, proyectos, procesos, actuaciones conjuntas y propuestas evaluativas. La polinización de la creatividad tiene lugar a través de proyectos de innovación curricular". (Saturnino de la Torre, 1997).
}

La importancia al alto nivel de pensamiento creativo en educación que De la Torre menciona, invita al lector a dar una mirada introspectiva a la forma en que evoluciona en su qué hacer profesional.

\subsubsection{Conceptos relacionados.}

La innovación va de la mano con la mejora continua. La diferencia es que en la mejora continua se ven resultados a corto plazo, y los cambios son graduales, mientras que en la innovación se notan grandes cambios y se pueden ver resultados a mediano plazo. Mientras que la mejora continua es orientada al proceso, la innovación va orientada al resultado final.

Como proceso, la innovación educativa se desarrolla a través de la definición, construcción y participación social, es decir, siempre debería estar relacionada a un grupo de personas insertas en un mundo globalizado, lo cual insta a entender su carácter multidimensional (socio tecnológico o estratégico, político, ideológico, cultural, contextual, biográfico) y a evitar el hecho de cambiar por cambiar sólo por las exigencias gubernamentales o Institucionales, sin una reflexión seria, crítica y deliberada sobre que cambiar, en qué dirección, cómo hacerlo y con qué medios. La innovación merece ser pensada en términos de tensión utópica, con la mirada en el ideal considerando realidades y encontrando el punto medio que acerca a ambos conceptos. Supone además una apuesta por lo colectivamente construido como esperable o deseable por la imaginación creadora, por la transformación de lo existente; por lo que la sociedad requiere; equivale también a la creación de un clima propicio para 
indagar, descubrir, ensayar, reflexionar, criticar, evaluar. Es más un proceso de capacitación y crecimiento personal e institucional que de implementación de programas o incorporación de nuevas tecnologías, aunque estas se encuentran muy bien posicionadas y han llegado a hacerse necesarias, quienes las manejan finalmente son los responsables de darle valor a aquello que es útil para el desarrollo de aprendizajes significativos. El hombre no debe ser reemplazado por las máquinas y su pensamiento debe ser una constante de creación para el uso de cualquier herramienta sustentable para la educación, pero: ¿Qué es el hombre sin reflexión? ¿Qué puede lograr un docente sin un previo espacio de pensamiento crítico de su qué hacer? ¿Qué hace un docente sin considerar la innovación en días como hoy? No pueden agotarse en enunciados de principios, ni de ensayos esporádicos o experienciales, sino que han de orientarse a la internalización o institucionalización de los cambios, entendida esta como la consolidación de los objetivos previstos, de nuevas conductas personales u organizativas, normas o patrones de funcionamiento, de gestión y desarrollo.

Se requiere articular una serie de procesos y establecer una estructura de diversos roles complementarios. Ahora bien la escuela como unidad de cambio educativo ha de generar un conjunto de estrategias que lo apoyen y gestionen desde su origen hasta su internalización. El centro debe desarrollar capacidades para: a) Diagnosticar su propia situación y desarrollo, b) Movilizar planes de acción conjuntos, y c) Evaluar tanto su implementación como sus resultados. Pero finalmente quien lleva a la realidad todas estas aspiraciones o exigencias son los docentes, aquellos que en aula logran los cambios más potentes que tienen resultados insospechados.

En la práctica educativa, la innovación está ligada a la creatividad y eso implica, el reconocimiento de un problema, la identificación de formas de resolverlo, la toma de decisiones para lograrlo y la puesta en marcha de acciones innovadoras.

La innovación es una dimensión de cambio que conlleva mejorar los objetos o las condiciones en que opera un proceso humano. Es poner al día los sistemas educativos, transformando las prácticas educativas para adecuar su calidad a los requerimientos personales y sociales de formación humana, científica, cultural y profesional. Es un proceso de indagación de nuevas ideas, paradigmas, propuestas y aportaciones para la solución de problemas de la práctica educativa.

Cualquier innovación introduce novedades que provocan cambios; esos cambios pueden ser drásticos (se deja de hacer las cosas como se hacían antes para hacerlas de otra forma) o progresivos (se hacen de forma parecida pero introduciendo alguna novedad); en cualquier caso el cambio siempre mejora lo cambiado; es decir, la innovación sirve para mejorar algo. La mejora 
puede ser la obtención de estudiantes más seguros, hábiles y con comprensión de los aprendizajes, también puede ser la reducción del esfuerzo; aumentar la rapidez en obtener resultados; aumentar calidad, satisfacer nuevas demandas, etc.

La teoría de la innovación, podríamos decir que desde el final del siglo pasado, ha sido el último intento por controlar gestionando de un modo racionalista, los procesos de cambio educativo, considerando el progreso socioeconómico, sin embargo esto ya ha ido decayendo. Hoy es complejo con todas las libertades impuestas en la vida de los humanos poder controlar los procesos de cambios y las disposiciones al mismo. Por lo que resulta interesante constatar cuales serían los factores que se asocian al éxito o fracaso de innovación en el aula donde estarían incluidos los procesos. Por ejemplo: Tiempo que se otorga a un docente para la reflexión de su qué hacer profesional; Resistencia al cambio; Conocimiento más acabado del historial académico de los estudiantes; autoconocimiento de factores socioemocionales del docente; relaciones interpersonales saludables entre pares; comunicación fluida del equipo de gestión y docentes en aula; Convicción y concordancia de objetivos propuestos por la institución y llevados a cabo por la docencia, inclusión de la innovación como parte activa de la enseñanza aprendizaje, etc,. Mientras tanto en el cruce de caminos, en el acomodo y/o adaptación a los procesos de cambios, actualmente aún tenemos que acogernos a las lecciones aprendidas sobre cómo promover la innovación. Siempre es interesante dar una mirada retrospectiva a la educación.

José Tejada, viene a recoger, de modo sistematizado, una cierta crónica de lo que hemos aprendido acerca del cambio educativo. Tejada defiende, contra postilustrados o neoconservadores que ya no creen en el progreso, que:

"el cambio es siempre positivo, en virtud del carácter intrinseco de mejora que lleva implíito el término en educación"

Podríamos graficar Innovación como un ciclo de mejora continua de la calidad:
Ciclo de mejora continua

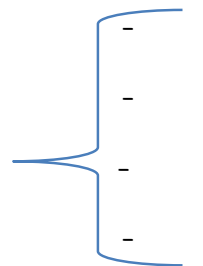
Planificar
Actuar
Evaluar
Rectificar, corregir.

"Innovar= Mejorar= Calidad Educativa" 


\subsection{Influencia de la Comunicación - sentipensar - Educar sintiendo la propuesta innovadora.}

Etimológicamente, comunicación deriva del latín cummunis: poner en común algo con otro. Y cummunis proviene del griego koinoonia, que significa a la vez comunicación y comunidad; es decir, existe una estrecha relación entre comunicarse y estar en comunidad. Es el mismo origen de comunidad, de comunión; expresa algo que se comparte: que se tiene o se vive en común. Comunicación es común unión. Cuando nos comunicamos, nos relacionamos con los demás y somos escuchados en condiciones de igualdad. La comunicación no es un simple agregado a la convivencia, sino un hecho realmente esencial, intrínseco a la esencia misma del hombre como ser social.

Solamente existe una relación genuina de comunicación cuando interactúan interlocutores que hablan y escuchan sin el ánimo de imponerse o de manipular, cuando se da un proceso de elaboración y comprensión mental de los mensajes, y cuando se producen efectos de convivencia y una situación de auténtica reciprocidad entre las personas que dialogan.

Entonces para poder comunicarnos ¿qué necesitamos? Básicamente hablamos de un emisor, mensaje y receptor en términos generales. Sin embargo, comunicarse es más que eso. Comunicarse es poder mirarse, verse y ver a los otros. Es ampliar la mirada a nuevos paradigmas. Es tener las herramientas suficientes como para poder transmitir informaciones, decisiones, ideas, predisponer positivamente en forma ideal al receptor y lograr que este se transforme en emisor, donde se genere una comunicación fluida en la cual ambos se realicen y disminuyan las situaciones complejas que generalmente se pueden dar en ambientes educacionales y en definitiva se alcancen los objetivos propuestos. Entendiendo que a medida que permitamos que los demás se expresen, participen y confronten la realidad, de acuerdo con su forma de percibirla, interpretarla y vivirla, estaremos posibilitando un mejor entendimiento. Escuchar a las personas que piensan distinto no implica que debamos necesariamente cambiar de opinión, sino simplemente escuchar: dejar entrar la información, y luego decidir. El mundo caminará hacia un auténtico personalismo en el momento en el cual seamos capaces de reconocer al otro como persona, y esto implica reconocerlo como ser de posibilidades.

Comunicarse lleva implícito el intercambiar, compartir, dialogar de manera recíproca, involucra el respeto y el derecho a ser diferentes, a pensar distinto, a ver la vida con otros matices, implica reconocer la diversidad y no incomodarse en ella; esto es innovar también y debe comenzar desde quien educa, no es posible pretender que quienes van a instruirse y aprender den la iniciativa. Pues quien educa, debe llevar la intención previa a una 
reflexión, considerando el enfoque de las habilidades que pretende desarrollar.

Los educadores, son quienes forman parte de esa red invisible, de esa otra mirada que llamamos nuevo paradigma. La Innovación en el aula. Son los ejes que liberan o reprimen el pensamiento y progreso de los estudiantes.

Es lamentable reconocer que hemos convertido la educación en hacer pensar solamente, en aprender contenidos, en desarrollar especialidades a la perfección, en hacer reflexionar a los alumnos; sin embargo, el sentir lo hemos dejado fuera del aula, todo se ha ido mecanizando, y aun cuando la tecnología es una herramienta poderosa y positiva al servicio de la educación, el ser humano se ha ido alejando de su esencia, de lo que lo convierte en "hombre", el sentir. Cuando sentimos, interiorizamos, grabamos, lo que ingresa a nuestros sentidos permanece y eso queda por tiempos ya que el sentir provoca un impacto emocional. Daniel Goleman (1997: 299) menciona que:

"...las destrezas emocionales como el autoconocimiento, la identificación, expresión y el manejo de los sentimientos, el control de los impulsos y las gratificaciones demoradas y el manejo del estrés y la ansiedad, son habilidades clave para conocer la diferencia entre sentimientos $y$ acciones y el aprendizaje de cómo tomar mejores decisiones emocionales mediante el control del impulso a actuar, identificando luego acciones alternativas y las consecuencias posteriores a la acción”.
Esto inevitablemente nos lleva a pensar en que el conocimiento de uno mismo; el conocimiento que el docente obtenga de su propia reflexión, será la vertiente emocional que formará parte de ese nuevo paradigma que tanto se requiere.

Hasta ahora nos han enseñado que las cosas son secuenciadas, ordenadas, pautadas y que el todo es otra cosa. Sin embargo la pretensión de este trabajo es poder vivir la innovación y comprender que el todo y cada una de sus partes se comunican. Lo global, lo holístico, el significado que se comunica con los pequeños elementos y esto, el camino al éxito. Lo importante es lograr dar significancia a la globalidad, al silencio, a los tiempos y a sus partes.

Por lo tanto es posible afirmar que la innovación se da en un contexto comunicacional. Lo que indica que es necesario considerar lo que dice la comunidad estudiantil, sus requerimientos, además de conceder espacios a nuestras voces como docentes, lo que esperamos, anhelamos, si queremos trascender en la educación o simplemente vaciar contenidos. Por este motivo cabe preguntarse...

a) ¿Cuándo un docente está preparado para la innovación?

b) ¿Cuáles son las condiciones en que la mayoría de educadores "por vocación" se encuentran frente a la innovación?

c) ¿Por qué esto genera resistencia? 
d) ¿Es necesario contar con educadoresdocentes que tengan una autoestima saludable?

e) ¿Cree usted que es necesario conocerse para crear instancias de innovación en el aula?

\subsection{Fenomenología del Conocer}

El tema fenomenología del conocer invita a viajar a un escenario cotidiano, conocido y hasta agradable a ratos, haremos el ejercicio mental de trasladarnos a uno de esos momentos gratos de la vida...Les invito a imaginar el placer que se siente cuando uno tiene que ir a un supermercado. Si ustedes van a un supermercado se moverán por los pasillos observando, viendo en los productos variadas utilidades, tomando esto aquí, mirando esto allá, dejando una cosa y reteniendo otra, imaginando lo beneficioso que será para su hogar. En este proceso se moverán con una libertad, con soltura, con un placer existencial grande por el hecho de poder decidir sin límite más que el de sus posibilidades económicas. $\mathrm{Y}$ es ahí, en ese paso que justamente viene el dolor y es cuando uno tiene que pagar, pero antes de tener que sostener ese desagrado necesario para poder llevar lo que elegimos, es decir, pagar, uno lo pasa bien, se siente a gusto, hasta contento. Tan bien como cuando una va al campo donde tiene árboles frutales y al pasar por el huerto, come frutas las cuales toma libremente de los árboles moviéndose con soltura en un mundo generoso y abierto. De hecho, cada vez que uno imagina su descanso, lo imagina probablemente en lugares que en nuestro imaginario equivalen al descanso, por ejemplo: la playa, en el campo, tendido al sol, tomado un juguito bien helado, la piscina, una tarde de deporte, escuchar una buena música, moviéndose en un mundo natural que tiene que ver con lo más espontáneo de uno, su ser y ese ser enfrentado a la ausencia necesaria de las presiones cotidianas, más bien en un ambiente de quietud y paz.

Por otro lado, quisiera llevarles a un escenario un poco diferente pero que es muy cotidiano, y es hacer referencia a lo que le acontece a uno cuando alguien le pide limosna. Le aseguraría que la mayoría de ustedes dan, o explican por qué no dan, buscando una justificación para el acto de no dar. ¿Por qué? , porque el compartir es parte de nuestra esencia, la cual se da a través del diálogo, del intercambio, de la relación de hallarse en correspondencia, en reciprocidad. Es a través del proceso de intercambio como los seres humanos establecen relaciones entre sí y pasan de la existencia individual aislada a la existencia comunitaria. Por lo tanto cuando a uno le piden, uno siente como un tirón, que no es algo meramente cultural de una norma social que prescribe ayudar al prójimo. La petición de compartir le tira a uno las entrañas, se genera una empatía con el otro y si uno no da, uno se siente en problemas.

Otra cosa a la cual podemos hacer referencia es a una noción bajo la cual nos movemos actualmente en una descripción de lo 
social que desconoce justamente lo dicho en el párrafo anterior. Nos referimos a la noción de convivencia. Vivimos inmersos en una sociedad que enfatiza la competencia como valor social, pero la competencia es esencialmente antisocial. Etimológicamente la competencia es la correspondencia para que alguien pueda exigir o pedir lo que le corresponde y que ha sido pretendido por otro. Esta acepción etimológica implica que la competencia es una atribución del poder del ejercicio de la actividad de otro y constitutivamente la negación del otro, porque involucra un fenómeno en el que el éxito de uno se funda en el fracaso de otro. Por ejemplo: observemos un partido de futbol o voleibol vibrante, la derrota del contrario es central para la victoria del ganador. Estamos inmersos en un cuento que valida la competencia como un bien social aunque sabemos que la competencia es destructora de la convivencia humana. El fenómeno social se funda en el compartir. No en competir.

Finalmente quisiera hacer referencia a que, como ciudadanos de una nación moderna, nos enfrentamos a un problema que no admite solución técnica porque involucra una contradicción ética. Me refiero a la continua creación de miseria en la aparente abundancia. En efecto, por una parte nos sabemos poseedores de técnicas productivas que en principio nos permite producir una cantidad ilimitada de cualquier cosa, y satisfacer todas las necesidades humanas si las aplicamos de manera adecuada y controlada porque lo queremos así. Por otra parte, nuestro modo fundamental de vivir es de seres inmersos en un mundo de recursos ilimitados que pueden ser apropiados competitivamente. El resultado es la producción con apropiación excluyente que lleva a la riqueza de unos y la miseria de otros. Y esto será así mientras validemos la apropiación competitiva como conducta legítima a pesar de su carácter constitutivamente antisocial. Claro está que la otra solución es que la miseria del prójimo no nos importe, pero es a la larga difícil, porque la solidaridad tiene fundamento en nuestra esencia de seres humanos. Por lo tanto la innovación en estas circunstancias es necesaria y evidente. La educación traspasada a estos niveles favorece el pensamiento crítico y reflexivo de nuestros estudiantes, lo que les hará convertirse en mejores personas y ciudadanos responsables de sus actos.

Desde la experiencia, la Fenomenología del Conocer permite que con frecuencia nos demos cuenta de que vemos lo que no vemos y de que no vemos lo que vemos. Por ejemplo, biológicamente existe el llamado "punto ciego" el que se encuentra en cada ojo en el cual no vemos nada porque es la salida del nervio óptico donde no hay foto receptores, pero no andamos con un agujero en el mundo. Llenamos el hueco. Si no lo hacemos nos sentimos vulnerables, desorientados, vacíos. Si damos una mirada cargada de honestidad a nuestro mundo interior, continuamente estamos llenando huecos 
perceptuales, huecos de puntos ciegos que tenemos debido a nuestra estructura anatómica, a nuestra estructura conductual, o a nuestra estructura cultural. Lo hacemos constantemente. ¿Y con qué lo llenamos?, los llenamos con lo que somos. Y somos a partir de nuestra percepción. El acto de la percepción por tanto no es nunca una mera repetición del mundo exterior, no es como si fotografiásemos el mundo valiéndonos de nuestros órganos sensoriales y receptivos. Estamos tan acostumbrados a que las cosas nos parezcan tal y como las vemos que ni siquiera pensamos que pudiera ser de otro modo. El acto físico de percibir actitudes sensoriales lo llamamos percepción. Pero el proceso de la percepción se diferencia mucho de la sensación.

La percepción nos permite distinguir y diferenciar unas cosas de otras, nuestro ser del mundo, nuestra realidad de las otras cosas. Y esto es muy necesario considerarlo, ya que para conseguir la innovación desde la docencia para el logro de habilidades en el aula, es relevante la percepción, el comprender y entender al otro, conocer y distinguir a cada uno con sus propias potencialidades, no esperando un resultado igual en cada estudiante, ni siquiera en la reacción de mis pares docentes.

La experiencia de la percepción es el fundamento de la experiencia cognoscitiva. Y la experiencia también nos dice que muchas veces nuestras respuestas a un sinfín de preguntas no son suficientes para el interlocutor, o para nuestros estudiantes, ya que cada uno frecuentemente tiene su propia respuesta a cada pregunta que se genere. Con esto quiero hacerles notar que cada uno oye lo que oye. Esto lo sabemos y existen referencias muy antiguas; tal vez la más conocida se encuentra en el Nuevo Testamento; cuando Jesús dice: “el que tenga oídos para oír, que oiga; el que tenga ojos para ver, que vea”. Este fenómeno es mucho más trascendental de lo que corrientemente pensamos. Cada uno oye desde su perspectiva, y oye lo que oye desde sí mismo. Cada uno al oír se revela. Esto tiene que ver con otra cosa más general, que es la multiplicidad de los dominios cognoscitivos en los cuales existimos cada uno determinado por un modo de oír, que es también un modo de determinar qué es aceptable y qué no, en ese dominio.

Existen múltiples dominios cognoscitivos, una religión por ejemplo, tiene ciertos criterios que especifican qué afirmaciones pertenecen a ella y que le son propias lo cual lo define y determina. Las ideologías políticas también son dominios cognoscitivos, ya que especifica que conjunto de afirmaciones constituyen las afirmaciones que le son propias como ideologías políticas y cuáles no. Los juegos son dominios cognoscitivos. Esto es aparente en el hecho de que cada vez que se inventa un juego, lo que se inventa es un conjunto de reglas que deben ser satisfechas para estar en el juego. Si no se satisfacen las reglas no se está en el juego, se está fuera de él. Si no estudias, no avanzas, si no avanzas te estancas... En general 
todo criterio de validación conductual determina un dominio cognoscitivo.

El fenómeno del conocer, no es solo saber cosas; no es sólo resolver problemas, lo cual generalmente estamos entendiendo como "conocer" más bien hemos querido explicar que: conocer, es también tener una conducta efectiva en el ámbito especificado por una pregunta. Más aún, quien hace la pregunta determina el ámbito en el que él o ella quieren la respuesta a su pregunta. $\mathrm{Y}$ esto es lo que hacemos como profesores por ejemplo, cuando queremos determinar si un alumno sabe algo o no. Preguntamos y esperamos una conducta efectiva en el ámbito definido por la pregunta. Pero... ¿Hemos analizado si la pregunta está bien definida para obtener una respuesta efectiva? Debemos recordar que nuestros alumnos son seres individuales, son unidades específicas, con características que los distinguen y personalizan, por tanto es necesario afinar nuestro criterio y considerar las diferencias que nuestros estudiantes puedan presentar para que exista un aprendizaje significativo del cual tanto se habla. Y esto no es trivial, ya que la historia individual de un ser humano forja su futuro y en esto la educación, usted y yo somos responsables.

El niño que llega a adulto siendo un respetable ciudadano, como el niño que llega a adulto siendo un despreciable terrorista, se han movido en correspondencia con su medio. Su adaptación tiene que ver con lo observado, con lo escuchado, con sus sentidos, con la percepción. Y la educación en este sentido cobra vital relevancia, porque la diferencia que hará un docente que reflexiona, innova, crea, con uno que solo trabaja por cumplir, puede afectar de manera potente la vida de seres humanos en evolución. Todo ser humano existe en su nicho, en su medio y mientras realiza su nicho, existe. En general y en un sentido metafórico, un ser vivo sólo ve su nicho y para él nada existe más allá o más acá: lo que no ve, no es, y lo que ve, es. Nosotros como profesores no podemos ver directamente el nicho donde se desarrollan nuestros alumnos, ya que muchas veces ellos lo ocultan. Lo que vemos probablemente es el entorno, su ambiente. Y en este sentido es que la labor docente es fundamental. En nuestras manos se encuentran vidas de seres humanos perceptivos, que requieren de otros humanos que consigan entregarles herramientas no solo en el ámbito intelectual sino también herramientas para la vida, que les enseñen que hay un mundo más allá de su mundo.

\subsection{HABILIDADES... un concepto necesario en la praxis}

"La Habilidad es la capacidad de una persona para hacer una cosa correctamente y con facilidad". Desde la creatividad y la Innovación, la habilidad para pensar de forma creativa, viene dada, en una tercera parte, por la genética y, en las dos terceras partes restantes, por el aprendizaje. 
Desde la antigüedad Platón señala que la creatividad es el entusiasmo que se arrastra fuera de uno mismo. Para Aristóteles, la creatividad era un proceso racional originado en la naturaleza. Ahora bien cabe preguntarse: ¿Cómo desarrollar habilidades para innovar?

Y esta pregunta nos invita nuevamente a la reflexión en cuanto al desarrollo de habilidades cognitivas en los estudiantes.

En primer lugar es menester considerar propósitos, ya que sin estos no hay rumbo.

\section{PROPÓSITOS}

Considerar al alumno como centro de atención durante la clase.

Concentrar el proceso educativo en el aprendizaje.

Utilizar estrategias para el diagnóstico del progreso de sus alumnos paralelamente a la estimulación de los mismos.

Lograr que el alumno "aprenda a aprender" (metaconocimiento).

Para el logro de dichos propósitos debe de existir la fragmentación del acto educativo idealmente en cuatro factores fundamentales:

I. El rol del profesor como mediador del proceso y como facilitador del aprendizaje.

II. La metodología de enseñanza basada en procesos.
III. La orientación en el diseño de los materiales instruccionales del alumno y del docente.

IV. El monitoreo y transferencia del aprendizaje a otras áreas académicas y a la vida cotidiana del alumno.

Considerando estos datos, al momento de crear nuevas formas de enseñar en el aula, se generará la confianza que con bastante frecuencia se escapa de nuestro raciocinio docente y transmitiremos con mayor seguridad lo que es necesario para el avance no solo académico sino vital.

\subsection{Asertividad, competencias necesarias para innovar}

Podemos comenzar diciendo que la asertividad es una habilidad. La asertividad como tal no es más que la presentación de manera respetuosa y justa de nuestros, derechos, sentimientos e ideas ante los demás, dejando clara nuestra posición de manera concisa y no olvidando el papel que nos corresponde dentro de algún esquema en que nos encontremos insertos, desarrollándose a través de nuestra experiencia diaria (nuestra interacción con las demás personas), y está ligada tanto a nuestra personalidad como al carácter, además puesto que ambos no son estáticos sino que se moldean con la interacción social a lo largo de la vida, entonces 
puede considerarse a la asertividad, como algo que evoluciona en función de la propia evolución de nuestro ser social y de nuestros conocimientos, lo cual convierte a la asertividad en un amplio concepto que engloba aspectos propios de cada persona, como lo son la autoestima, la falta de confianza, así como la cultura e intelecto.

La asertividad se va desarrollando desde la infancia y es ahí cuando empezamos a formar un concepto de nosotros, de acuerdo a como nos ven nuestros padres, compañeros, amigos, etc., tomando en consideración cada una de las experiencias que vamos adquiriendo. $\mathrm{La}$ asertividad juega el rol de método y guía para abrirnos paso hacia la excelencia en las relaciones con los demás, en el ámbito laboral a través de su práctica genera oportunidades y reduce brechas entre las personas, aumenta la buena percepción que los demás tienen de nosotros, y forma parte de las estrategias para avanzar hasta las metas y objetivos propuestos. Hasta hace unos años atrás, ser asertivo, como también tener iniciativa, autogestión, liderazgo, motivación de logro y desarrollo, búsqueda activa de soluciones, innovación y mejoras, no era algo que se esperara de las personas en el trabajo. Más bien, se valoraba la obediencia, el apego a las funciones asignadas, $\mathrm{y}$ la capacidad para llevar a acabo fielmente las tareas tal como habían sido concebidas en su planificación. Hoy como todos sabemos el mundo ha cambiado, sin que lo hayamos advertido plenamente como para alcanzar a hacer los ajustes necesarios. Y en el trabajo, los requerimientos y expectativas sobre las personas también cambiaron. Hoy cada vez más se espera que las personas asuman compromisos y protagonismo sobre los resultados de su trabajo, mejoren la productividad y calidad, sean verdaderos innovadores por medio de un mejor desempeño, y sean capaces de corregir ellas mismas las dificultades que aparecen en el camino. Proveyendo a los estudiantes de una diversidad de facultades y capacidades a adquirir.

$\mathrm{Y}$ aquí es donde la asertividad empieza a ser significativa, relevante en el mundo del trabajo, entre otras habilidades importantes dignas de cuidar y desarrollar. En efecto, como se ha mencionado anteriormente, ya no sirve que una persona responda a su jefe sobre un mal resultado argumentando que no se le entregaron bien las instrucciones, ya que se espera que ésta tenga la iniciativa para solicitar la información que le falta, para exigir anticipadamente aquello que necesita para realizar las funciones y tareas que le corresponden.

Agregar además que es una habilidad de expresar las propias ideas de forma adecuada, con respeto a los intereses de los demás, manifestar sin mayor dificultad nuestras necesidades, deseos, opiniones, sentimientos y creencias de forma honesta, directa y apropiada, de tal manera que nos sintamos satisfechos con nosotros mismos, sin menospreciar o desalentar los derechos e intereses de otras personas. 
Según Jakubowski y Lange (1978), la asertividad se conceptualiza como la capacidad de hacer valer los derechos, expresando lo que uno cree, siente y quiere en forma directa, honesta y de manera apropiada, respetando los derechos de la otra persona.

Es probable que en el transcurso de su vida laboral, se haya encontrado alguna vez frente a situaciones difíciles y comportamientos problemáticos de otras personas.

Por ejemplo habrá estado más de una vez en alguna de estas situaciones:

- Experimentar dificultades al hablar en una clase. - Sentir irritación por la falta de colaboración de otras personas.

- Sentir frustración cuando sus alumnos no prestan atención y se distraen con facilidad, entendiéndose comúnmente que usted no tiene dominio de grupo, o que ellos son indisciplinados.

- Sentir exigencia laboral y falta de empatía de parte de sus pares, directivos u otros.

Las mencionadas anteriormente son una de las tantas situaciones complejas que como docentes debemos enfrentar. Sin embargo al haber escogido esta carrera en el transcurso del tiempo hemos podido adquirir herramientas útiles para continuar con nuestra moral dignamente y con la convicción de que somos quienes preparamos el futuro de nuestro país.
Ya hablamos acerca de la comunicación y sus efectos, comprendimos que su influencia en educación es potente y que bien realizada con la utilización adecuada de habilidades con propósitos se pueden alcanzar metas impensadas. Sin embargo si comunicamos sin asertividad, lamentablemente los objetivos son poco probables de cumplir.

La conducta asertiva debe partir, obviamente, del profesor. Quienes hemos sido designados para asistir como docentes en una sala de clases, vivimos la experiencia de ser "administradores" de todo lo que ocurre en el aula, incluido el clima socio-afectivo y disciplinar, generado a través de nuestra proyección modélica y asertiva.

Todo esto nos lleva a pensar detenidamente y a autoevaluar dos de las más importantes habilidades del profesor:

a) La comunicación didáctica, $y$

b) La interacción afectiva dentro y fuera de la sala de clases.

La primera habilidad, nos conduce a pensar que no todo tipo de comunicación impacta positivamente en el aprendizaje y en la formación integral del alumno. Una comunicación agresiva en la sala de clase traerá como consecuencia inmediata una represión de las opiniones y sentimientos de cualquier persona que interactúa en un grupo, influyendo negativamente en la 
estima y en la formación de su auto concepto, especialmente cuando esta comunicación agresiva conlleva un mensaje peyorativo y minimizador.

Es entonces cuando necesitamos encontrar un tipo específico de conducta que mejore la relación profesor-alumno dentro de una institución educativa.

\subsubsection{Comportamiento asertivo en docencia.}

El objetivo de una conducta asertiva es satisfacer las necesidades y deseos de todas las partes involucradas en la situación.

Intentaremos comprender y evaluar las herramientas básicas de la asertividad, con el fin de descubrir áreas de oportunidad en la labor docente.

Características básicas de un profesor asertivo.

Se propone una lista, que no sólo caracteriza a un profesor asertivo, sino a toda persona inmersa en un marco de convivencia social armónica. Esta lista es la siguiente:

1.- Usa el lenguaje de los sentimientos.

2.- Habla de sí mismo y expresa sus percepciones. 3.- Acepta y da cumplidos.

4.- Utiliza lenguaje claro y apropiado.

5.- Cuando expresa desacuerdo, lo hace con respeto.

6.- Pide clarificación y pregunta por qué.
7.- Habla por sus derechos.

8.- Se manifiesta libremente como es.

9.- Se comunica fácilmente con todos.

10.- Tiene alta autoestima.

11.- Se respeta a sí mismo.

12.- Acepta o rechaza libremente de su mundo emocional a otras personas.

13.- No dice "no" cuando quiere decir "si", ni "si" cuando quiere decir "no".

14.- Reconoce sus debilidades y fortalezas.

15.- Tiene una gran autoconfianza para tomar decisiones.

16.- Sabe elogiar y reconocer el trabajo de los demás.

17.- Es sensible a los distintos contextos y procura responder.

Creemos que esta lista puede ampliarse de manera infinita ya que en, en el fondo, las conductas asertivas conforman una suerte de integralidad humana, que socialmente está vinculada a nuestra propia perfectibilidad como seres humanos. Considerando que es mejorable a lo largo de la vida.

\subsubsection{Asertividad, comunicación verbal, no verbal y feed-back.}

Algunos pasos básicos de la asertividad son: 
1. Escuchar atentamente lo que se dice. Mostrar a la otra persona que le presta atención y la atiende.

2. Decir lo que se piensa u opina. Permite expresar los propios sentimientos o pensamientos, sin insistir o pedir disculpas.

3. Decir lo que se desea que suceda. Hay que hacerlo de forma clara y directa, sin vacilar ni insistir.

En la actividad docente, es habitual que en la sala de clases se identifiquen distintos tipos de alumnos. Se encuentra a aquellos colaboradores, siempre dispuestos a ayudar al profesor. También, aquellos tímidos, callados y taciturnos que jamás crean conflictos ni con docentes ni con sus pares; también nos encontramos con los displicentes, que "no están ni ahí" con lo que pasa en el aula; y junto a ellos los "aportilladores" de clases que gritan a los cuatro vientos los errores del profesor. La lista es grande, pero en todos ellos, el factor común es la necesidad de ser tratados - todos, sin excepción- a través de una adecuada comunicación asertiva y la comunicación manifestada a través de la conducta. Para esto, podemos definir la conducta en términos generales, como la forma de comportarse de una persona; es decir el modo de reaccionar un ser vivo ante el medio que lo rodea. Según Owens (1976), "la conducta es el resultado de los estímulos del medio ambiente".

En el plano educativo, conviene señalar que la conducta de los interactuantes no sólo responde a lo que una persona hace y cómo lo hace, sino que también es importante saber por qué y para qué hace o deja de hacer.

Partiendo de este punto, Bower (1980), clasifica tres tipos de conductas en una persona:

1.- Conducta pasiva o no asertiva.

2.- Conducta agresiva.

3.- Conducta asertiva.

Si nosotros como profesores podemos distinguirlas en nuestros alumnos, seremos capaces de actuar ordenada y oportunamente en aquellos momentos críticos que nos corresponde actuar frente a los alumnos.

Nuestra claridad de apropiación permitirá, además, prospectar e identificar los posibles escenarios y los roles de los participantes en la interacción didáctica, convirtiéndonos en docentes eficaces y efectivos en la hora de actuar.

No está demás señalar que las conductas siempre reflejan algún tipo de sentimiento o emoción que, definitivamente, se tiene que expresar; por tal razón, nuestra conducta asertiva como docentes deberá expresarse sin ambigüedades.

A continuación presentamos tres cuadros que pueden ser útiles para nuestra labor docente: 
Asertividad Y Comunicación Verbal

\begin{tabular}{|c|c|c|}
\hline Comunicación Asertiva & Comunicación Agresiva & Comunicación No Asertiva \\
\hline $\begin{array}{l}\text { - Se basa en comentarios breves, claros } \\
\text { y directos. } \\
\text { - Utiliza adecuadamente el yo. } \\
\text { - Distingue entre hechos y realiza } \\
\text { crítica constructiva, sin acusaciones } \\
\text { ni culpabilidades. } \\
\text { - Utiliza preguntas abiertas para } \\
\text { indagar los pensamientos, las } \\
\text { opiniones, las necesidades y los } \\
\text { deseos. } \\
\text { - Se enfoca hacia la solución. }\end{array}$ & $\begin{array}{l}\text { - Es seca, cortante, soberbia. } \\
\text { - Utiliza en exceso el YO y el MI. } \\
\text { - Confunde las opiniones con los } \\
\text { hechos. } \\
\text { - Culpabiliza a los demás. } \\
\text { - Utiliza preguntas amenazantes, } \\
\text { el sarcasmo y otras actitudes de } \\
\text { humillación y de disminución de } \\
\text { la autoestima de los demás. } \\
\text { - No conduce hacia ninguna } \\
\text { solución. }\end{array}$ & $\begin{array}{l}\text { - Los comentarios son largos y confusos. } \\
\text { - Muy poca utilización del YO. } \\
\text { - Apela a palabras y frases de relleno: } \\
\text { Debería, tendría que, quisiera. Frecuencia } \\
\text { de justificaciones. } \\
\text { - Excesivas peticiones de perdón y de } \\
\text { permiso. Uso de comentarios como: soy } \\
\text { un inútil, no sirvo para nada, todo me sale } \\
\text { mal. } \\
\text { - Usa frases que quitan importancia a } \\
\text { nuestras necesidades y objetivos: bueno, } \\
\text { en realidad no importa. }\end{array}$ \\
\hline
\end{tabular}

\section{Asertividad Y Comunicación No Verbal}

\begin{tabular}{|c|c|c|c|}
\hline & NO ASERTIVA & ASERTIVA & AGRESIVA \\
\hline $\mathrm{VOZ}$ & $\begin{array}{l}\text {-Débil } \\
\text { - Vacilante } \\
\text { - Demasiado suave. }\end{array}$ & $\begin{array}{l}\text { - Firme sostenida. } \\
\text { - Tono variado. } \\
\text { - Claro, enfático. }\end{array}$ & $\begin{array}{l}\text { - Muy firme. } \\
\text { - Sarcástico o frío. } \\
\text { - Estridente, chillona. }\end{array}$ \\
\hline Pautas de emisión & $\begin{array}{l}\text {-Dubitativa, con muchas pausas. } \\
\text { - Cambios bruscos de velocidad. } \\
\text {-Frecuentes carraspeos }\end{array}$ & $\begin{array}{l}\text {-Fluidez sin vacilación. } \\
\text { - Énfasis en palabras clave. } \\
\text { - Ritmo sostenido. }\end{array}$ & $\begin{array}{l}\text { - Totalmente fluido. } \\
\text { - Énfasis en palabras } \\
\text { acusatorias. } \\
\text { - Muy rápido. }\end{array}$ \\
\hline Expresión facial & $\begin{array}{l}\text {-Sonrisa insegura cuando está } \\
\text { enfadado o si le critican. } \\
\text { - Arruga el ceño cuando está } \\
\text { enfadado. } \\
\text { - Boca apretada, falta de control. }\end{array}$ & $\begin{array}{l}\text { - Sonríe cuando está contento } \\
\text { o satisfecho. } \\
\text { - Frunce el ceño. } \\
\text { - Normalmente faz relajada. }\end{array}$ & $\begin{array}{l}\text { - Sonrisa retorcida o irónica } \\
\text { - Cejas arqueadas. } \\
\text { - Barbilla hacia arriba. }\end{array}$ \\
\hline Contacto Ocular & $\begin{array}{l}\text {-Evasivo. } \\
\text { - Mirada baja. }\end{array}$ & - Mirada directa o retadora. & $\begin{array}{l}\text { - Mirada de arriba abajo. } \\
\text { - Apunta con el dedo. }\end{array}$ \\
\hline $\begin{array}{l}\text { Movimientos } \\
\text { corporales }\end{array}$ & $\begin{array}{l}\text {-Manos torcidas o apretadas. } \\
\text { - Hombros encogidos. } \\
\text { - Manos en la boca. } \\
\text { - Movimiento nervioso. }\end{array}$ & $\begin{array}{l}\text { - Movimientos amplios y } \\
\text { pausados de manos y brazos. } \\
\text { - Brazos cruzados en señal de } \\
\text { protección. } \\
\text { - Sentado en forma recta o } \\
\text { relajada. } \\
\text { - Cabeza recta. }\end{array}$ & $\begin{array}{l}\text { - Golpea con el puño. } \\
\text { - Brazos cruzados en señal de } \\
\text { alejamiento. } \\
\text { - Camina alrededor. } \\
\text { - Cabeza inclinada. }\end{array}$ \\
\hline
\end{tabular}


La Asertividad Y E1 Feed-Back

\begin{tabular}{|c|c|}
\hline \multicolumn{2}{|l|}{ ESTRATEGIA ANTES DE LA SITUACIÓN } \\
\hline PASOS & COMENTARIOS \\
\hline -Identificar la situación & $\begin{array}{l}\text {-Especificar quien está implicado. } \\
\text {-Identificar mis necesidades y/o deseos. }\end{array}$ \\
\hline $\begin{array}{l}\text {-Prever el inicio de la intervención (escenas más } \\
\text { temidas) }\end{array}$ & $\begin{array}{l}\text {-Experimentar internamente el diálogo. } \\
\text {-Forzar el diálogo con las peores respuestas posibles } \\
\text { ante ellos: ¿Cómo reaccionaría? }\end{array}$ \\
\hline -Cuestionar el diálogo & $\begin{array}{l}\text {-Identificar elementos erróneos. } \\
\text {-Imaginar las exageraciones, suposiciones y } \\
\text { generalizaciones. }\end{array}$ \\
\hline -Convertir el diálogo defectuoso en correcto. & $\begin{array}{l}\text {-Reemplazar los elementos erróneos por elementos } \\
\text { correctos. } \\
\text { - Asegurarse de que aparecen: } \\
\text { a) Mis derechos. } \\
\text { b) Los derechos de los otros. } \\
\text { c) Mi conducta previsible. }\end{array}$ \\
\hline -Practicar el diálogo interno correcto & -Practicarlo hasta que resulte cómodo \\
\hline -Describir los sentimientos & $\begin{array}{l}\text {-Describir que se siente ante la situación. } \\
\text {-Si hay sentimientos negativos, revisar de nuevo el } \\
\text { diálogo interno. }\end{array}$ \\
\hline
\end{tabular}

\begin{tabular}{|l|l|}
\hline \multicolumn{2}{|l|}{ ESTRATEGIA DURANTE LA SITUACIÓN } \\
\hline PASOS & COMENTARIOS \\
\hline -Tomarse un respiro & -Mientras el otro habla o justo antes de contestar \\
\hline -Recordar lo ensayado & -Utilizar frases yo y describir conductas \\
\hline -Meditar las respuestas. & $\begin{array}{l}\text {-Con frases de introducción: ya veo, déjame que lo } \\
\text { piense. }\end{array}$ \\
\hline
\end{tabular}

\subsubsection{Asertividad y manejo de conflicto.}

El diccionario define "conflicto" como derivado del latin conflictus que significa "luchar juntos”. Algunos sinónimos de la palabra son: “desacuerdo", "guerra", "batalla” y “colisión”. En otras palabras, significa demostrar antagonismo por algo, o luchar en una "batalla" determinada.

Los conflictos son muy comunes en las relaciones humanas, $\mathrm{y}$, en el caso de nosotros los profesores, no somos excepción. 
A continuación, trataremos la f) El tiempo.

problemática del conflicto desde una perspectiva interesante.

a) Conflicto del profesor con la organización (centro educativo).

b) Conflicto del profesor con los alumnos (sala de clases).

c) Conflicto del profesor con los apoderados (centro de padres o individuales).

d) Conflicto del profesor con la organización (centro educativo)

En realidad, antes de continuar, es necesario dejar claro que las organizaciones no "tienen" conflictos, sino que hay en ellas gente que los narra y que, al hacerlo, los significa como tales. El conflicto es una construcción del hombre; o sea es vivida como conflicto, sólo si es significada como tal. De allí entonces que, más allá del carácter subjetivo que asume, es necesario conocer que algo será indicado por alguien como conflicto, en el marco de una estructura de significación.

Podemos detectar seis elementos para la significación de los conflictos:
a) La identidad.
b) El sistema político.
c) La racionalidad dominante.
d) Los sistemas de trabajo.
e) El espacio.

a) La identidad. Constituye un elemento esencial de la organización, siendo su razón de ser y su existir. En una organización como la escolar, los conflictos de identidad remecen hasta sus propios fundamentos. Es como si dijéramos; una escuela que no eduque, una iglesia que no edifique la moral y espiritualmente, o un ejercicio que no prepare para la lucha.

b) El sistema político en el cual se inscribe la organización. Por lo general estos sistemas son autocráticos o democráticos, creando estilos de acción y lenguajes distintos. Cualquier desviación a lo prescrito por los sistemas políticos genera conflictos organizacionales, que repercuten en quienes ejercen acciones de liderazgo ofensivo o, como se dice popularmente, "atornillan al revés" del sistema de turno.

c) La racionalidad. Se refiere, en líneas generales, al paradigma que está definiendo el curso de las acciones y políticas generales en una organización. Por ejemplo: las escuelas privadas imponen una racionalidad dominante de tipo económico, pues es la vía que les permite sostenerse como organización. En este tipo de colegios no es posible "expulsar sin más" a un alumno, ya que significa una fuente de recursos económicos que se pierde. En muchas ocasiones los profesores nos vemos envueltos en conflictos 
organizacionales cuando nuestra forma de ver las cosas no coincide con la racionalidad que se ha impuesto la organización. En este caso es importante recordar el adagio: "no vale la pena nadar contra la corriente" exponiéndose a perder el trabajo, o romper frontalmente con los directivos de la organización. Sin embargo - que conste - no se trata de incentivar el conformismo sino que atenerse a una realidad que no podríamos cambiar individualmente.

d) Los sistemas de trabajo. Constituyen el cuarto elemento a tener en cuenta en un conflicto organizacional, ya que son determinantes en los modos de relación entre personas. Por ejemplo, no es lo mismo un colegio donde el director es "trabajólico" y determina un fuerte y acelerado ritmo laboral, que otro donde el director es "laissez-faire", haciendo más relajador el ambiente laboral. Se crea conflicto cuando un trabajador laissez-faire ingresa a una organización laboral "trabajólica" y viceversa.

e) El espacio. Es el quinto elemento donde se ubica el conflicto en una organización. Este espacio es más bien metafórico, pudiendo considerarse los siguientes:

- Espacio Físico. Oficinas, pasillos, espacios abiertos y cerrados.

- Espacio Comunicativo. Basado en preguntas como: ¿Quién es el emisor y quién el receptor? ¿Qué canales son abiertos y permitidos?
¿Qué papel juega el profesor en la generación y solución de conflictos? Etc.

f) El Tiempo. Este elemento es muy importante para los efectos de su duración e intervención oportuna.

Temporalmente los conflictos se desarrollan en tres momentos.

1. Escalamiento, donde los actores en disputa, se enfrentan en un escenario de intenciones y acciones previas.

2. Confrontación propiamente tal, donde las fuerzas opositoras llegan al máximo de lucha o disputa.

3. Des escalamiento, correspondiente al "enfriamiento" de las fuerzas en conflicto, donde el fervor decae triunfando uno de los elementos confrontacionales, o produciéndose un consenso.

\section{Creatividad en Acción.}

¿Es usted una persona creativa? Es probable que no le sea fácil contestar de inmediato la pregunta porque para muchas personas lo creativo está referido a los artistas, a los inventores o a los sabios y también a momentos de iluminación que ocurren sólo algunas veces en la vida.

En este taller creemos que toda persona posee una capacidad creativa y es posible desarrollarla en cuanto se experimenta conforme a las oportunidades que se le brinda. 
Podríamos decir que se trata de una capacidad inherente a todo ser humano y que, sin embargo, al correr el tiempo suele ser dejada por influencias de múltiples hechos, entre otros el rol de algunas instituciones que apelan a la normatividad y a la repetición mecánica de conceptos e interpretación de realidades.

A modo de ejemplo, se puede mencionar que muchas veces la educación recibida ha privilegiado el razonamiento lógico dejando fuera la intuición y otras formas de pensamiento menos estructuradas que favorecen la creatividad.

El punto de partida en esta sesión será reconocerse en esta capacidad y descubrir los mecanismos que atentan a ella, para luego pasar a las aplicaciones de acuerdo a los intereses iniciales señalados y así enriquecer la capacidad creativa que cada uno presente a través del desarrollo de la capacidad de análisis, de la libertad de expresión, el pensamiento crítico e innovador y, a partir de ello promover su aplicación en su lugar de trabajo.

A menudo, consideramos la actitud innovadora y la creativa como una virtud que todo docente debe poseer intrínsecamente para conseguir unos resultados espectaculares en el aprendizaje de sus alumnos. Basta con haber pasado por un centro educativo, ya sea como alumno o como profesor para darse cuenta de que no es así. Ni todos los docentes son innovadores, ni todos son creativos.

¿Cómo reconocer si eres un docente creativo?
El docente creativo, modifica su entorno, lo adapta en su beneficio y en el de sus fines. Fruto de ese ejercicio en su mente nacen nuevas técnicas y materiales cuya versatilidad le permite apoyarse en diferentes plataformas, aplicaciones o prácticas, sin depender explícitamente de una u otra. El profesor creativo se adapta, y lo hace porque tiene capacidad para enfrentarse a los imprevistos, no se le ponen los pelos de punta cuando se va la luz y acepta e integra al momento un texto que un alumno ha obtenido de internet en el que cuestiona aquello que el día anterior enseñó en clase.

Un entusiasta de la creatividad en la enseñanza, el docente creativo, conoce al alumno, le saca una sonrisa, no es individualista, nunca lleva la clase cerrada, promueve la participación, es colaborador y es generoso con sus materiales porque no los considera suyos, sino una evolución de lo que otros crearon para él.

En cuanto al aprendizaje, es nuestra intención hacer presente la necesidad de identificar algunos roles en un proceso creativo:

- El investigador o científico

- El artista

- El juez o evaluador

- El rastreador o guía.

Estos roles pueden estar personalizados, es decir, encontrar personas que presenten uno de ellos en particular pero que sobre todo 
corresponden a distintos momentos y requerimientos, y de los cuales no se puede prescindir.

Metodología.

Lo anterior constituye una propuesta metodológica que persigue demostrar de un modo básico, las etapas del proceso creativo que pueden servir de herramientas en el proceso de aprendizaje.

En efecto, se trata de cuatro dimensiones ejemplificadoras que hacen del proceso creativo un aporte a la innovación:

\section{El Científico:}

$1^{\circ}$ Necesidad de contar con una información adecuada y pertinente. Hoy cada vez es más evidente, que se requiere contar con datos precisos para responder mejor a los problemas que surgen.

El Artista:

$2^{\circ}$ Las ideas de nuestra capacidad "artística". Tienen que ser muchas ideas, es decir, mientras más ideas, mejor, aunque a simple vista aparezcan como descabelladas o fuera de foco.

El Juez:

$3^{\circ}$ La dimensión selectiva: relación de las ideas con la información y la evaluación de la factibilidad. En todo caso, siempre conviene mantener más de una alternativa de solución.
El Rastreador:

$4^{\circ}$ Es la capacidad de seguir la evolución de los problemas y de sus soluciones y de volver a insistir con una nueva posibilidad hasta llegar a la meta perseguida.

Si pensamos en nosotros mismos en relación a lo explicado es probable que nos sintamos cómodos en una dimensión pero con carencia en otras. La invitación en este sentido, es tomar conciencia de los dominios que tenemos para reforzarlos, pero también identificar las debilidades para asumirlas. En esto consiste el camino propuesto para la innovación educativa.

En esta perspectiva consideraremos que la innovación puede comenzar a tener efectos concretos cuando surgen pequeños logros en acciones impulsados por hombres y mujeres entregadas a la docencia, quienes estarán en condiciones de contestar en forma positiva a la pregunta inicial ¿es usted una persona creativa?

\subsection{Encontrar sentido en la incertidumbre avanzando hacia el éxito y realización personal.}

Los tiempos que estamos viviendo son muy confusos, porque muchas de las cosas que daban forma a nuestra vida están desapareciendo. Las instituciones en que nos basábamos, especialmente la organización del trabajo, ya no son tan seguras o tan ciertas. Las organizaciones 
de trabajo están desapareciendo muy rápidamente en los últimos tiempos.

$\mathrm{Si}$ dirigimos la mirada hacia otras instituciones -la ley, las estructuras políticas, la monarquía- encontramos que también ellas están siendo cuestionadas. Son ídolos con pies de barro; descubrimos que están guiadas por meros mortales. Por tanto, es comprensible que nos sintamos muy inseguros en lo referente al futuro. Para poder alcanzar cierto sentido de cohesión, creo que, utilizando al máximo nuestras mejores habilidades, debemos tratar de descubrir cómo va a ser el futuro. Eso es lo que voy a intentar hacer. Quiero convencer a la gente de que hay, al fin y al cabo, algún sentido en todo el enorme sin sentido que nos rodea.

El conjunto parece ser caótico, pero caos tal vez no sea la palabra justa para describirlo. Desde el punto de vista de la ciencia, el caos no es caótico. De hecho, el caos explica que hay una estructura subyacente en todas las cosas y que existen razones para que se produzcan determinadas situaciones. Pero también hay espacios en las razones, por lo cual se puede realmente actuar en el resultado final de las cosas. $\mathrm{Y}$ es eso lo que encuentro tan tremendamente apasionante en medio de toda esta incertidumbre, incluso anarquía, en que nos hallamos inmersos. Porque esto significa que el futuro no está previamente ordenado, ni siquiera en la ciencia, lo cual significa que un pequeño movimiento de las alas de una mariposa, o yo mismo haciendo algo, puede hacer que el mundo cambie un poquito.

Hasta cierto punto, el escenario parece ser pesimista sobre el futuro porque es posible percibirlo como tiempos difíciles. Pero muy en el fondo podemos estar optimistas porque es posible percibirlo como una época de grandes oportunidades para muchos individuos que nunca pensaron que podrían influir en el mundo.

\subsubsection{Paradojas.}

Si vamos a intentar encontrar algún sentido en toda esta confusión que nos rodea, especialmente en el ámbito de la educación, que es lo que nos convoca, debemos hallar la manera de organizarla en nuestra mente para empezar a entender lo que realmente está sucediendo en el mundo e intentar hacer algo al respecto. ¿Cómo hacerlo?, tal vez aceptar que no existen respuestas simples o correctas a la vida, que está llena de contradicciones y sorpresas y que de hecho está llena de paradojas. Pero si podemos aprender a entender y aceptar estas paradojas, y aceptar que podemos llegar a encontrar un sendero a través de ellas, podremos convivir con ellas y manejarlas.

Esto es especialmente necesario cuando los tiempos se vuelven más turbulentos, porque en esos momentos el mundo se vuelve todavía más complejo y difícil de entender. De hecho, en cualquier parte adonde dirijamos la mirada, la paradoja parece ser la compañera del progreso. 
Lo que la paradoja nos invita a pensar es que dos pensamientos opuestos pueden ser ciertos al mismo tiempo. Por ejemplo, uno puede estar enamorado de una persona, la cual, en determinados momentos, le puede desagradar. Puede desear al mismo tiempo la continuidad y el cambio y tenerlos ambos. Lo que debemos hacer es aprender a equilibrar los opuestos. Es como montar en un columpio. Uno tiene que saber que para que el columpio funcione, tiene que haber una sucesión de movimientos ascendentes y movimientos descendentes y que ambos opuestos son necesarios para conseguir que el columpio se mueva, un juego en que el movimiento y la emoción se producen por el equilibrio entre contrarios, porque es inevitable que la vida esté llena de paradojas. Creo que la clave para el progreso, e incluso para sobrevivir en la vida y tener éxito, es darse cuenta de que las contradicciones pueden coexistir, y aprender a vivir con ellas.

Por ejemplo, idealmente las organizaciones educativas deberían ser centralizadas y descentralizadas al mismo tiempo. Ser globales y locales al mismo tiempo. Diferenciadas e integradas. Muy ajustadas y sueltas. Tienen que hacer planes a largo plazo y, sin embargo, seguir siendo flexibles. Sus trabajadores deben ser más autónomos pero, por otra parte, estar integrados a un equipo. Pero el hecho es que no podemos dejar que todo esto confunda a la gente. Debemos encontrar la manera de vivir y trabajar con este tipo de contradicciones para reconciliar los opuestos en vez de vernos obligados a elegir entre ellos.

No creo que la mayoría de las personas puedan manejar la paradoja con facilidad, por lo cual tendremos que intentar hacer la vida más simple para entenderlo. La primera medida que podría tomarse sería conseguir que las personas se diesen cuenta de que existe la paradoja y de que la solución no es sencilla. No existe un camino fácil hacia la gloria y la felicidad en la vida. Pero, por otra parte, necesitamos dar cierta estructura a las cosas para que sea más fácil aprender a manejar la paradoja.

\subsubsection{Espacio, libertad y responsabilidad de ejecución laboral.}

Uno de los retos que enfrentan las organizaciones educativas es dar a la gente espacio para actuar con iniciativa pero siendo capaces, al mismo tiempo, de definir el éxito. La razón por la que algunas personas trabajan tanto, demasiado, con frecuencia me parece que es porque no hay límites. Sus directivos no paran de decirles que deben trabajar con más intensidad, que deben tener logros, cumplir con las metas. No pueden lanzar una mirada atrás y decir: "Ha sido un gran año", porque siempre piensan que podría haber sido mejor.

Como docentes empoderados de la situación actual y de los muchos desafíos que 
enfrentamos a diario debemos pensar en que nuestra labor tiene gran relación con el cómo construimos sobre las premisas de la planificación, la predecibilidad y el cumplimiento de exigencias. A pesar de esta inseguridad es preciso actuar. A veces tendremos que tomar decisiones y estar preparados para revocarlas o abandonarlas si resultan incorrectas. Estamos viviendo en un mundo diferente. Debemos aprender a vivir con el caos y la incertidumbre, tratar de sentirnos cómodos con ella y no buscar certeza donde no la hay. Sólo podremos lograrlo entrando en la incertidumbre e intentando crear, dentro de ella, nuestras propias islas de seguridad. No estamos hablando aquí de la seguridad contractual dentro de una organización educativa, como un contrato de empleo, el éxito en el aula, etc. La nueva forma de seguridad será psicológica y personal. Será la creencia de que si la cosa no funciona, siempre podemos hacer algo más. Uno es su propia seguridad. Debemos encontrar una seguridad personal también en nuestras relaciones. No estamos hechos para estar solos, necesitamos un sentido de conexión, debemos sentir que el hecho que estemos aquí les importa a otras personas, porque si no importa que estemos o no estemos ahí, empezamos a pensar que nuestra vida no tiene ningún sentido. Si no tenemos ninguna conexión con nadie, no tenemos ninguna responsabilidad y, por tanto, ningún propósito.

Inventando el futuro. No podemos mirar hacia el futuro como una continuación del pasado.
Las cosas que lo llevaron a usted a donde está no le van a ayudar mantenerse allí. Pero, por otra parte, si no sabe de dónde viene le será difícil avanzar. En realidad, debemos ver el futuro como una serie de discontinuidades y debemos aprender a seguir el paso.

Es interesante utilizar la metáfora de la segunda curva, la segunda parte de la llamada curva sigmoidal. La curva sigmoidal, o en forma de $\mathrm{S}$, describe el modo en que se desarrollan los hechos en la vida real. Comienza con un valle y a continuación, gracias a la suerte o a una buena administración, crecen y elevan la curva, pero al final, declinan. Todo sufre una decadencia.

Esto pasa con imperios, corporaciones, ciclos de vida de un centro educativo, relaciones, e incluso la vida misma. La única forma en que se puede crecer de manera continuada en el futuro es creando una nueva curva antes de que la primera empiece a descender, lo cual significa tener constantemente inventiva y creatividad.

Últimamente ha estado de moda describirse a sí mismo como educadores solucionadores de problemas. Esto es totalmente falso porque cuando descubren el problema y lo solucionan ya están pasadas. Tienen que ir por delante del problema. Tienen que inventar el mundo. Tienen que crear la "segunda curva". Para que usted pueda volver a crearse, de cara al futuro, debe estar preparado para desembarazarse del pasado; en caso contrario, permanecerán encerradas en su curva actual y, tarde o temprano, 
desaparecerán. El arte está en no desembarazarse del pasado de una sola vez, no pueden abandonar la primera curva hasta que hayan acabado de construir la segunda. Por ello durante algún tiempo el pasado y el futuro tienen que coexistir en el presente, y ese es el camino a través de la paradoja.

La manera de entender uno el futuro, en las organizaciones educativas, en la sociedad y en su propia vida, es encargarse del futuro, no responder a él.

El hombre razonable reacciona al mundo, mientras que el hombre irrazonable trata de que el mundo reaccione a él. Por lo cual, todo el progreso (y debo agregar que todos los desastres también) son causados por personas irrazonables, que son las que realmente intentan cambiar el mundo. Lo que esto quiere decir es que no podemos esperar que nos ofrezcan un trabajo seguro y una larga carrera profesional; debemos decidir qué tipo de vida queremos llevar y salir, y hacer que suceda.

Esto requerirá que cambiemos completamente nuestro actual sistema educativo. Nuestras escuelas están diseñadas sobre el supuesto implícito de que todos los problemas del mundo han sido ya resueltos y que el profesor conoce todas las respuestas. El trabajo de un profesor es presentar el problema a los estudiantes, después la respuesta y, finalmente, instruirlos. Tal como yo veo el mundo, el mundo futuro en continua discontinuidad, los problemas todavía no han aparecido. Debemos inventar el mundo. La educación tradicional corre peligro de ser deshabilitadora, y no lo contrario. Muchos de los supuestos de la educación indicaban que había cosas "conocibles" del mundo, y que si uno las conocía, podría caminar por ese mundo con cierta seguridad. Ahora sé que he tenido que desaprender muchas de esas cosas.

La vida parece ser una sucesión de problemas abiertos que no parecen tener respuestas correctas, pero que a pesar de ello piden una respuesta. Solíamos pensar que la vida era un problema cerrado, que todo tenía una respuesta correcta, sólo que no la conocíamos todavía. Pero alguien la encontraba, generalmente alguien mayor y más experto que nosotros. Y con un poco de investigación, nosotros también encontraríamos esa respuesta.

Creo que sería necesario un sistema escolar totalmente diferente, algún sistema que no se base sólo en adquirir conocimientos y conocer hechos. Estos son todavía necesarios, por supuesto, pero son de fácil acceso. Así podemos hacer que el futuro tenga un sentido. Tenemos que darle nuestro propio sentido. De la misma manera, las organizaciones educativas tienen que construir su propio futuro. El mundo está a disposición del que quiera. Esto me parece a la vez apasionante y aterrador. Para hacer que sucedan las cosas en el futuro hemos de tener confianza en nosotros mismos y creer en nuestra propia valía. Esto es lo que las escuelas tendrían que enseñar. 
¿Usted cree que tendremos que redefinir nuestra perspectiva global sobre la forma en que funciona el mundo? Sí. Solíamos pensar que el mundo era, hasta cierto punto, un lugar racional gobernado por gente racional. Estamos descubriendo que, en realidad, es un lugar bastante confuso y desordenado y que no hay nadie encargado de él.

Este tremendo flujo de relaciones interpersonales corre de un lado a otro, y no podemos contarlo porque es literalmente invisible. ¿Cómo tratar a nuestros alumnos? ¿Cómo comprender a cada uno con sus individualidades?

Los gobiernos son incapaces de controlar lo que las personas hacen, dónde lo hacen, cómo lo hacen, porque ya no pueden ver mucho de ello o contarlo. En otras palabras, vivimos en un mundo que creíamos que estaba gobernado y cada vez está más ingobernado. Un mundo donde los antiguos métodos de control ya no funcionan. Las viejas fuentes de autoridad ya no llevan las riendas.

Cuando llegó la imprenta y pudimos por fin leer la Biblia en nuestra propia lengua en nuestras casas, y pudimos pensar sobre la vida, la moralidad y el orden social, descubrimos que muchas de esas instituciones tradicionales tenían los pies de barro. El rey y los sacerdotes se convirtieron en personas normales y corrientes, no mucho mejor -muchos de ellos- que el resto de los mortales. Eso fue muy emocionante porque nos permitió ser creativos y emprendedores. Llegamos a la época renacentista con todas las cosas magníficas que trajo consigo. Pero, al mismo tiempo, nos dio una gran inseguridad, mucha incertidumbre, facciones y guerras, pues los hombres rivalizaban unos contra otros para ocupar el puesto vacante de autoridad. Pienso que eso mismo está pasando ahora. Mientras que en aquella época la diferencia la marcó la aparición de la imprenta, ahora tenemos la televisión, los computadores, la red Internet y más.

Tenemos cantidades increíbles de información sobre todas las cosas, por lo cual todos podemos saber tanto como cualquier primer ministro o presidente, y probablemente disponemos de más tiempo libre que ellos para digerir toda la información. Podemos tener ideas propias sobre las cosas, y ello roba autoridad a las instituciones.

Le estamos dando a la sociedad una mente propia. Por una parte, esto es muy emocionante, porque puede llevarnos hacia un nuevo Renacimiento en el siglo XXI. Veremos mucha creatividad apareciendo por todas partes como pasó en el siglo XV, pero, a la vez, es muy aterrador porque la gente no está acostumbrada a no tener una autoridad cerca.

Eso es lo que quiero decir cuando hablo del "borde del caos". Es una expresión que los científicos utilizan para describir períodos de grandes turbulencias, cuando una nueva vida nace de la caída de la vieja. Cuando la complejidad y el caos se fusionan en un nuevo orden y nos encontramos en ese lugar al "borde del caos" hay 
un gran potencial para la creatividad, pero también por definición son un tiempo y un lugar muy difíciles y llenos de problemas.

Creo que es ahí donde nos encontramos en este momento. La promesa vacía del progreso ha resultado ser una promesa innocua. Esperábamos tener una sociedad más justa, más ordenada; una sociedad en la cual las personas tuviesen básicamente una vida sencilla, calmada y decente. Y no es así. Tenemos sociedades que están mucho más divididas de lo que quisiéramos porque en nuestra incansable búsqueda de la "eficiencia" estamos polarizándonos en los "tiene" y los "no tiene".

Nos estamos dando cuenta de que el trabajo cada vez puede resultar más apreciado o menos apreciado, por lo cual los ricos se vuelven cada vez más ricos y los pobres se vuelven cada vez más pobres, a veces en términos relativos y a veces en términos absolutos. Está emergiendo una clase baja y está creciendo una clase más alta aún.

Durante años hemos situado la búsqueda de la eficiencia y del crecimiento económico sobre todo lo demás porque entendíamos, que en ello consistía el camino hacía el "progreso". Pero lo hemos llevado a cabo a expensas de nuestros trabajadores, de nuestras comunidades y, tal como nos hemos dado cuenta en los últimos años, de nuestro medio ambiente. También hemos aplicado la idea de competitividad global a cosas que realmente no pertenecen a ese ámbito. Me refiero a actividades como la salud, la educación, el gobierno local, las organizaciones del bienestar social y las pequeñas industrias de servicios. Estas no tienen que competir con el mundo en cuanto a eficiencia de costos, pero insistiendo en que lo hagan estamos consiguiendo que el método y la eficiencia sean más importantes que el resultado. Esto es una manera incorrecta de pensar. En este proceso estamos creando una sociedad que no está a gusto consigo misma.

Esto es muy difícil de comprender porque es muy confuso. No es como una situación de guerra cuando uno sabe muy bien quién es el enemigo. Ahora el enemigo somos nosotros y nuestras sociedades, porque contra lo que estamos luchando es contra nuestro propio sistema de valores, nuestros propios principios. Estamos descubriendo que lo que creíamos que era correcto, es decir, ser más eficientes, trabajar con más ahínco y ser más ricos, no nos lleva al Nirvana que buscábamos.

Al menos no a todos. Lo cierto es que los que están consiguiendo más dinero son los que no están seguros de que valga la pena. ¿Quién quiere ser rico en la tumba? Y los que no están consiguiendo ganar dinero piensan que el mundo no tiene sentido porque el dinero es lo único que vale la pena poseer, y ellos no lo tienen.

La vida está hecha para vivirla, y, por supuesto, el trabajo forma parte de la vida pero hay más cosas. Por todas partes veo personas que van a la oficina cada día y vuelven de ella con sus maletines llenos de papeles para poder leerlos 
durante la noche y volver al día siguiente a la oficina para vaciar de nuevo sus maletines. Uno creería que esto se encuentra en la causa de alguna gran religión o cruzada, o sólo es una colosal pérdida de tiempo. ¿Por qué realizar todo eso sólo para hacer que los accionistas sean más ricos aún? Todavía tenemos que hacer un gran trabajo de redefinición fundamental si no queremos perder la carretera hacia el futuro que creíamos que el capitalismo había ganado. Y esto incluye la educación.

Debemos darnos cuenta de que la nueva fuente de riqueza es la inteligencia. No la tierra, ni el dinero, ni las materias primas, ni la tecnología; son los cerebros y las habilidades del ser humano. Los dueños del intelecto son los trabajadores.

Debemos darnos cuenta de que nuestra futura prosperidad depende de nuestras aptitudes y de nuestra educación, por lo cual tendremos que estar continuamente desarrollando y poniendo al día nuestras habilidades.

Debemos aprender a ver nuestra educación como una tarea de nunca acabar si queremos tener alguna participación en la nueva forma de propiedad. Encontrar un nuevo propósito.

Encuentro que a veces es útil mantenernos aparte para observar y darnos cuenta de que sólo somos una cosa ínfima en los ecos del tiempo y en los océanos del mundo y que sólo vamos a estar aquí durante un período de tiempo muy reducido.
No podemos cambiarlo todo o hacer del mundo un lugar perfecto. Pero, a pesar de eso, debemos intentar hacer lo máximo, porque creo que existe una razón por la cual estamos aquí, aunque sólo sea para que siga el espectáculo.

Me preocupa el hecho de que cada vez más gente encuentre que es aburridor seguir con el espectáculo, pues incluso tener hijos, por ejemplo, o hacer que nuestro centro educativo siga funcionando está dejando de ser un propósito. En lugar de ello, la vida se está convirtiendo para muchos en una existencia temporal, existencial e incluso egoísta donde lo que estamos tratando de hacer es vivir el momento. Sólo quedan unas pocas grandes causas.

Nuestra única razón en la vida es sobrevivir lo más confortablemente posible, una muestra de nuestro egoísmo. Siento, no obstante, que cada vez más gente quiere que la vida signifique más que eso. Ya no espera que los políticos se lo consigan sino que busca nuevas instituciones.

Considero que lo mejor y más satisfactorio en la vida es encontrar un sentido más allá de uno mismo. Si el propósito es sólo para uno mismo, tiende a disiparse con rapidez. Si uno no tiene una razón más allá de uno mismo, superior a uno mismo, acaba decepcionado al final. Por todo ello, es de considerar que debe existir un cambio en el significado de la educación, de cómo innovar en el aula y qué habilidades desarrollar, de tener un propósito para poder transmitir. 


\section{Conclusión}

El futuro va ser diferente en la medida que usted así lo desee y se lo proponga. Recuerde que es necesario en muchas ocasiones desaprender la forma en que actuamos en el pasado para poder actuar en el futuro. Por supuesto que el pasado es importante. Necesitamos tener un sentido de la historia, pero no podemos adentrarnos en el futuro mirando por encima del hombro. No podemos tropezar entrando en el futuro de espaldas. Si ingresamos al mundo de la educación y encontramos expuesta su historia pasada, debemos preocuparnos. Sin embargo, si ingresamos a la educación con una nueva mirada, con significado, con esperanza, considerando la innovación desde la docencia para el logro de habilidades como una herramienta inclusiva en el aula, que favorezca a seres humanos que sin saber buscan refugio, dirección, un sentido de vida, y pueda hacer la diferencia e incluso transformar sus propias vidas, y al mismo tiempo permitir reencontrarse y re encantarse con la esencia de la educación, vale el esfuerzo. Así visualizaremos el futuro con entusiasmo. Porque lo más emocionante del futuro es que podemos darle forma y el sello se lo puede dar usted".

\section{Referencias bibliográficas}

Barceló, M. G. (2005). ¿Por qué he dicho blanco si quería decir negro?: técnicas asertivas para el profesorado y formadores (Vol. 2). Graó.
Bracamonte, S. M. O., \& Calderón, G. Y. R. (2015). Clima motivacional de clase, asertividad y rendimiento académico en alumnos de la universidad césar vallejo. Revista de psicología, 7(1), 97-114.

Doz, R. A. (2007). Tejiendo la interculturalidad: actividades creativas para el aula (Vol. 14). Los libros de la Catarata.

Fueguel, C., \& Montoliu, M. R. (2000). Innovemos el aula: creatividad, grupo y dramatización.

Goleman, D. (1997). Inteligencia emocional. VERLAP SA.

Lipman, M., \& Sharp, A. M. (2002). La filosofía en el aula (Vol. 4). Ediciones de la Torre.

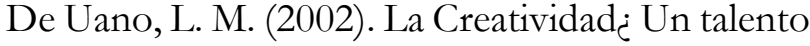
exclusivo de los artistas o una capacidad de todo ser humano?. Linhas criticas, 8(15), 265-288.

Mayer-Spiess, O. C. (1996). La asertividad: expresión de una sana autoestima. Desclée de brouwer.

Morejón, J. B., \& Sierra, M. D. L. D. V. (2005). Atmósferas creativas: juega, piensa y crea. Editorial El Manual Moderno.

Owens, R. G., \& Madrazo, J. M. (1976). La escuela como organización: tipos de conducta y práctica organizativa.

Rodríguez, M. I. S. (1999). Creatividad en educación. Univ. de Concepción, Dirección de Docencia.

Tejada, J. (Coord.) et al. (2009) Estrategias de innovación en la formación para el trabajo, Madrid: Tornapunta. 
Thorne, K. (2008). Motivación y creatividad en clase (Vol. 246). Grao.

Van der Hofstadt Román, C. J. (2005). El libro de las habilidades de comunicación. Ediciones Díaz de Santos.

Vieira, H. (2007). La comunicación en el aula: Relación profesor-alumno según el análisis transaccional (Vol. 179). Narcea Ediciones. 